
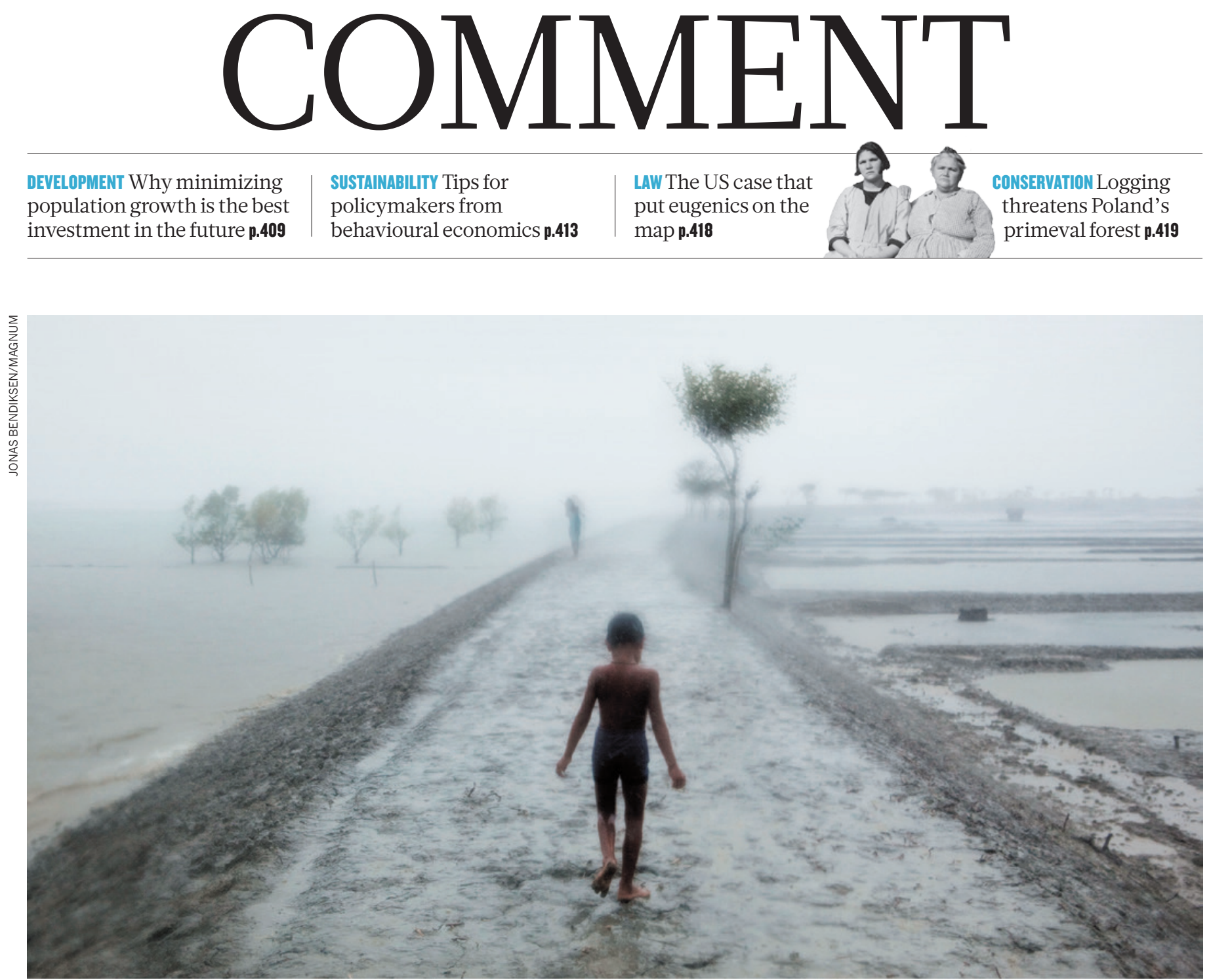

Sathkira District, Bangladesh, still flooded a year after 2009's Cyclone Aila.

\title{
Current climate models are grossly misleading
}

Nicholas Stern calls on scientists, engineers and economists to help policymakers by better modelling the immense risks to future generations, and the potential for action.

\section{$\mathrm{T}$}

he twin defining challenges of our century are overcoming poverty and managing climate change. If we can tackle these issues together, we will create a secure and prosperous world for generations to come. If we don't, the future is at grave risk.

Researchers across a range of disciplines must work together to help decision-makers in the public, private and non-profit sectors to rise to these challenges. Economists, in particular, need more help from scientists and engineers to devise models that provide better guidance about what will happen if we succeed or if we fail.

As the 2015 Paris agreement on climate change made clear, we must achieve a net-zero carbon economy this century. Doing so will require policies that drive

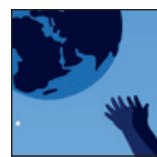
FUTURE GENERATIONS A Nature special issue nature.com/futuregenerations innovation, investment and entrepreneurship. The political will to make the necessary decisions depends partly on improving the analysis and estimates of the economics of climate change. Then the consequences of unmanaged global warming can be weighed much more transparently against the investments and innovations necessary to mitigate it.

Current economic models tend to underestimate seriously both the potential impacts of dangerous climate change and the 
wider benefits of a transition to lowcarbon growth. There is an urgent need for a new generation of models that give a more accurate picture.

\section{DARK IMPACTS}

The Fifth Assessment Report of the Intergovernmental Panel on Climate Change (IPCC), published in 2013 and 2014, provided a comprehensive overview of the literature on the costs of action and inaction. But the assessment understated the limitations of the research done so far. Essentially, it reported on a body of literature that had systematically and grossly underestimated the risks of unmanaged climate change. Furthermore, that literature had failed to capture the learning processes and economies of scale involved in radical structural and technical change, and the benefits of reducing fossil-fuel pollution, protecting biodiversity and forests, and so on.

The IPCC pointed out ${ }^{1}$ that estimates of losses resulting from a $2{ }^{\circ} \mathrm{C}$ increase in mean global temperature above pre-industrial levels ranged from $0.2 \%$ to $2 \%$ of global gross domestic product. It admitted that the global economic impacts are "difficult to estimate" and that attempts depend on a large number of "disputable" assumptions. Moreover, many estimates do not account for factors such as catastrophic changes and tipping points.

It is these hard-to-predict impacts that are the most troubling potential consequences of inaction. The next IPCC report needs to be based on a much more robust body of economics literature, which we must create now. It could make a crucial difference.

Many estimates of economic losses are based on the outputs of integrated assessment models (IAMs). These models attempt to combine the key elements of biophysical and economic systems. This is a worthy endeavour. Sadly, most IAMs struggle to incorporate the scale of the scientific risks, such as the thawing of permafrost, release of methane, and other potential tipping points. Furthermore, many of the largest potential impacts are omitted, such as widespread conflict as a result of large-scale human migration to escape the worst-affected areas.

For instance, there is evidence that temperature increases of $1.5^{\circ} \mathrm{C}$ and $2^{\circ} \mathrm{C}$ would lead to differing extents of sea-level rise and extreme weather events ${ }^{2}$, with obvious implications for small island states and coastal communities. These differences are simply not represented in the flawed estimates of economic losses.

IAMs are also used to calculate the social cost of carbon (SCC). They attempt to model the incremental change in, or damage to, global economic output resulting from 1 tonne of anthropogenic carbon dioxide emissions or equivalent. These SCC estimates are used by policymakers in cost-benefit analyses of climate-changemitigation policies.

Because the IAMs omit so many of the big risks, SCC estimates are often way too low. As a first step, the consequences being assessed should include the damages to human well-being and loss of life beyond simply reduced economic output. And the very large uncertainty, usually involving downward bias, in SCC estimates should always be made explicit.

As the IPCC acknowledged ${ }^{2}$, published SCC estimates "lie between a few dollars and several hundreds of dollars". These values often depend crucially on the 'discounting' used to translate future costs to current dollars. The high discount rates that predominate "Discount
rates are
central to any
discussion of
our hand in the
fate of future
generations." essentially assume that benefits to people in the future are much less important than benefits today.

These discount rates are central to any discussion of our hand in the fate of future generations. Most current models of climatechange impacts make two flawed assumptions: that people will be much wealthier in the future and that lives in the future are less important than lives now.

The former assumption ignores the great risks of severe damage and disruption to livelihoods from climate change. The latter assumption is 'discrimination by date of birth'. It is a value judgement that is rarely scrutinized, difficult to defend and in conflict with most moral codes.

\section{COSTING TRANSITION}

The other role of IAMs - to estimate the costs of climate-change mitigation - also suffers from major shortcomings.

The IPCC's mitigation assessment ${ }^{3}$ concluded from its review of IAM outputs that the reduction in emissions needed to provide a $66 \%$ chance of achieving the $2^{\circ} \mathrm{C}$ goal would cut overall global consumption by between $2.9 \%$ and $11.4 \%$ in 2100 . This was measured relative to a 'business as usual' scenario. Clearly, growth itself can be derailed by climate change from business-as-usual emissions.

So the business-as-usual baseline, against which costs of action are measured, conveys a profoundly misleading message to policymakers that there is an alternative option in which fossil fuels are consumed in ever greater quantities without any negative consequences to growth itself.

Crucially, IAMs generally omit the potentially huge costs of air pollution from fossil fuels - which are saved if alternative fuels are used ${ }^{4}$. IAMs struggle to describe developments in alternative energy. They fail, in general, to capture the feedback loops in the innovation process that interact across the economy, prompting institutional and behavioural change, possible discoveries and economies of scale. There is empirical evidence, for example, that the geographical location of researchers and inventors can affect whether a firm chooses to do clean or dirty innovation.

The initial investment required to catalyse the transition to a low-carbon pathway might lead to great economic benefits in the long run. These could go well beyond avoided climate risks ${ }^{5}$. The knowledge spillover from low-carbon innovation into the wider economy - for instance, a battery developed for electric vehicles being used in wheelchairs - seems to be greater overall than that from high-carbon-energy technologies ${ }^{6}$.

As engineers learn how to install, connect and repair technology cheaply, unit costs fall faster for many new technologies than for existing ones. This has already allowed solar-photovoltaic and onshore-wind technologies to become competitive with natural gas and coal in several locations, even without emissions taxation.

Also influential will be the emergence of new networks, such as the integration of electric-vehicle-energy storage into smart grids, as well as rapid technical progress. And these steps can be accelerated if, for example, consumers change behaviour and demand support for resource efficiency, recycling and pedestrianization. It is clear that much will depend on urban management and design; as cities grow rapidly, damaging infrastructure can become 'locked in'

\section{WHAT'S NEEDED?}

There is much that can be done to make the assumptions in standard IAMs more realistic with respect to the scale and nature of damages ${ }^{7,4}$. But to give policymakers the reliable information that they need when implementing the Paris agreement, incremental improvements ${ }^{7,8}$ to the present generation of IAMs may not be enough.

A comprehensive review of the problems of using IAMs in climate economics ${ }^{9}$ called for the research community to develop a "third wave" of models. The authors identify various types of model that might offer advances. Two are: dynamic stochastic computable general equilibrium (DSGE) models, and agent-based models (ABMs).

Like current IAMs, DSGE models can explicitly account for uncertainty about the future through the introduction of shocks, for instance, to economic output, consumption or climate damages ${ }^{10}$. ABMs, by contrast, 
os seek to provide more-realistic representations of socio-economics by simulating oे the economy through the interactions of of a large number of different agents, on the basis of specific rules. ABMs are widely $\checkmark$ used in finance, but have yet to be seriously applied to climate change. These are promising developments.

Now, a concerted effort is required by the research community to explore as many potential avenues as possible to better estimate the costs of action and inaction on climate change. The IPCC should distil what policymakers need to inform their decision-making. Learned societies and national academies must bring together researchers from a wide range of relevant disciplines to focus attention on improving economic modelling quickly.

Bangladeshi farmers and Cairo citydwellers are at severe risk of flooding and storms; southern Europe and parts of Africa and the Americas are threatened by desertification. Perhaps hundreds of millions of people may need to migrate as a result, posing an immense risk of conflict.

There is huge potential in future technologies that can drive change. These are omitted or badly underestimated in our current climate modelling - deeply damaging our guidance for policymaking. The well-being and prosperity of future generations are worth more.

Nicholas Stern is chair of the Grantham Research Institute on Climate Change and the Environment at the London School of Economics and Political Science (LSE), and president of the British Academy. e-mail:n.stern@lse.ac.uk

1. IPCC. Climate Change 2014: Impacts, Adaptation, and Vulnerability. Contribution of Working Group II to the Fifth Assessment Report of the Intergovernmental Panel on Climate Change (Cambridge Univ. Press, (2014).

2. Schaeffer, M. et al. Nature Clim. Change 2, 867-870 (2012).

3. IPCC. Climate Change 2014: Mitigation of Climate Change. Contribution of Working Group III to the Fifth Assessment Report of the Intergovernmental Panel on Climate Change (Cambridge Univ. Press, 2014).

4. Stern, N. Why are We Waiting?: The Logic, Urgency, and Promise of Tackling Climate Change (MIT Press, 2015).

5. Aghion, P. et al. Path Dependence, Innovation and the Economics of Climate Change (Grantham Research Inst., 2014).

6. Dechezleprêtre, A., Martin, R. \& Mohnen, M. Knowledge Spillovers from Clean and Dirty Technologies: A Patent Citation Analysis (Grantham Research Inst., 2013).

7. Dietz, S. \& Stern, N. Econ. J. 583, 574-620 (2015).

8. Gillingham, K. et al. National Bureau of Economic Research Working Paper No. 21637 (2015); available at http://dx.doi. org/10.3386/w21637

9. Farmer, J. D., Hepburn, C., Mealy, P. \& Teytelboym, A. Environ. Res. Econ. 62, 329-357 (2015).

10.Golosov, M. et al. Econometrica 82, 41-88 (2014).

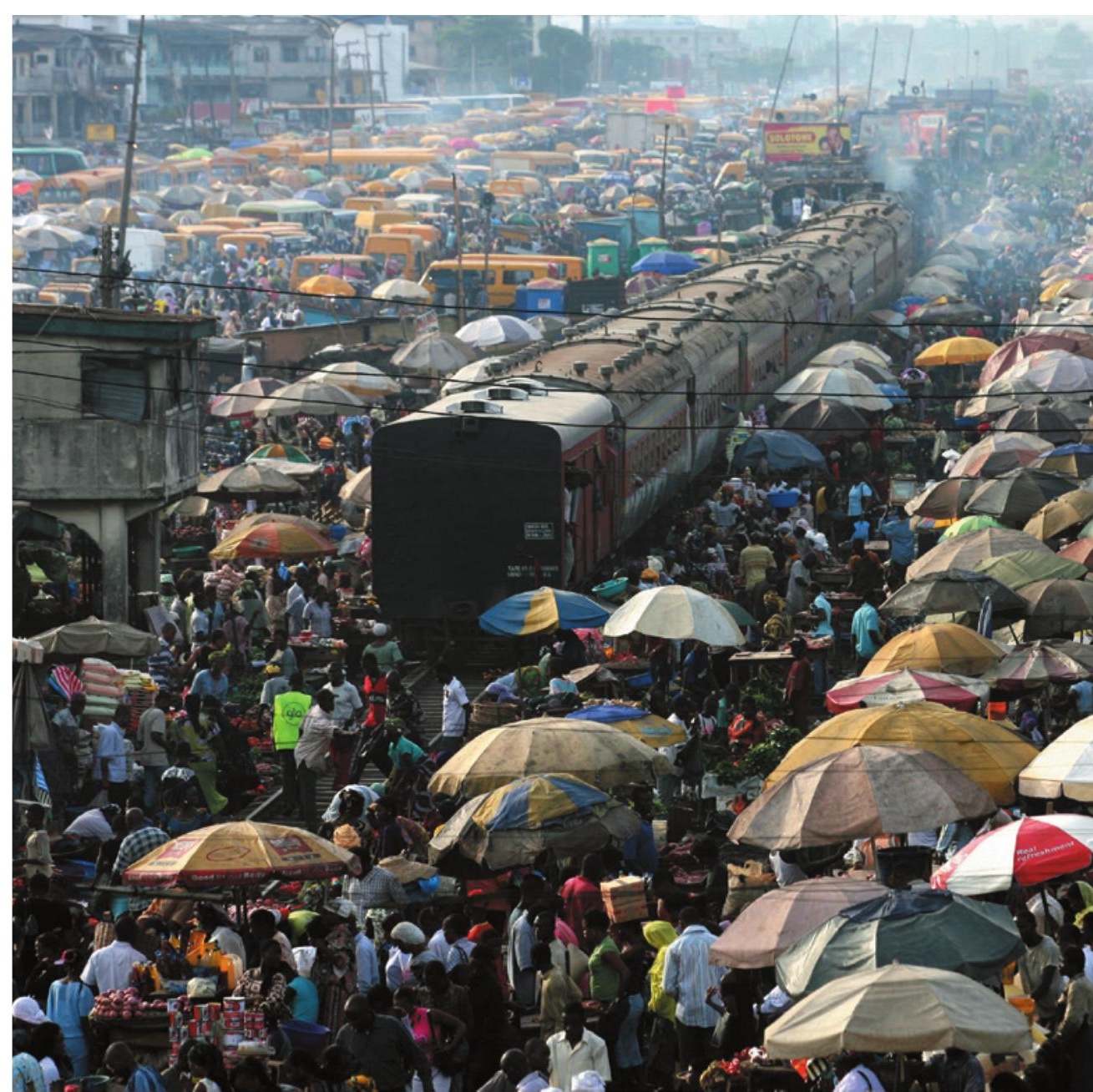

Oshodi market in Lagos.

\title{
Slow down
}

population growth

\author{
Within a decade, women everywhere should have \\ access to quality contraceptive services, \\ argues John Bongaarts.
}

I n 2100, our planet is expected to be home to 11.2 billion people. That's a more than $50 \%$ increase on today's 7.3 billion $^{1}$. This expansion of humanity is likely to be spread unevenly across the world. In the most developed regions, we expect declines (such as in Europe and east Asia) or little further growth (as in the Americas; see 'Bulges, gaps and shifts'). Substantial further growth

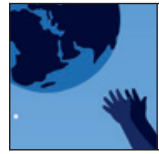

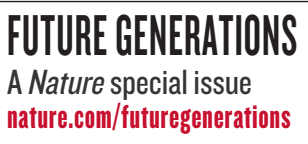

is anticipated in the least developed regions of south and west Asia (including in India and Pakistan) and north Africa (for example, in Egypt). By far the largest increase is projected in sub-Saharan Africa with a quadrupling of population - from just shy of 1 billion currently to 3.9 billion.

This potential addition of 4 billion people to the poorest regions of the globe is an obstacle to development that makes it difficult to be optimistic about their futures. Rapid population growth, with attendant consumption and waste, has pervasive adverse effects on societies 